\title{
Seeing With Sound: Educational Insights of the 200th Anniversary of Laennec's Magnum Opus
}

\author{
Amer M.Mohiuddin BS \\ Richard B.Gunderman MD, PhD
}

School of Medicine, Indiana University, 702 North Barnhill Drive, Room 1053, Indianapolis, IN 46202

The year 2019 is an auspicious year to reflect on the history of sound in medical diagnosis. Today many of us take largely for granted the existence of ultrasound and its central role in evaluating organs such as the thyroid gland, breast, uterus, ovaries, and testes, as well as the developing fetus. But the use of sound to detect alterations in internal structure and function reaches further back into the history of medicine, to the introduction of auscultation and percussion.

Until the invention of the ultrasound transducer, medicine's most important acoustic tool was the stethoscope, first described in a seminal treatise published 200 years ago by Rene Laennec.

Noteworthy in its own right, the story of Laennec and his discovery also bears important insights for contemporary educators and learners.

\section{LAENNEC}

This is the author's manuscript of the work published in final edited form as:

Mohiuddin, A. M., \& Gunderman, R. B. (2019). Seeing With Sound: Educational Insights of the 200th Anniversary of Laennec's Magnum Opus. Academic Radiology, 26(12), 1726-1727.

https://doi.org/10.1016/j.acra.2019.09.002 
Laennec was born in 1781 in the French city of Quimper. In a pattern too often replicated in the lives of Laennec and those he knew, when he was only 5 years old his mother died of tuberculosis. He and his brother went to live with their uncle, who was dean of the medical faculty at Nantes and helped steer Laennec to medicine.

At the age of only 14, Laennec was helping to care for the French Revolution's sick and wounded. At 18, he served as a surgeon in a military hospital, followed by medical studies in Paris. There he received instruction from some of the greatest physicians of the age, including Bichat (the father of modern histology), Corvisart (Napoleon's personal physician), and Dupuytren (the brilliant surgeon after whom the eponymous contracture is named) $(1,2)$.

Laennec's curiosity, powers of intellect, and dedication were all on display during his student days. Along with some of his teachers, he founded an anatomical society to enable students to share anatomical and pathologic findings with one another $(1,3)$. He described and coined the term melanoma, realizing that lesions found in the lungs of a patient were not carbon deposits but rather metastases $(4,5)$. Laennec published other papers on peritonitis, liver disease, and amenorrhea.

In recognition of the quality of his work, he received the medical school's first prize (1). His interest in the humane and ethical dimensions of medicine were reflected in his thesis, which he published at age 23, "The Application of the Hippocratic Doctrine to the Practice of Medicine" $(1,4)$.

Laennec learned of the publication of Corvisart's French translation of Viennese physician Leopold Auenbrugger's treatise on the use of percussion in thoracic diagnosis. Disappointed not to receive an appointment to the faculty of medicine, he entered private practice, with the aim of 
improving physical diagnosis by correlating in vivo observations with postmortem pathology, focusing especially on diseases of the lungs.

These efforts were aided when Laennec accepted an appointment at the Necker Hospital, which enabled him to closely correlate clinical and pathologic findings of the patients he cared for. Laennec recognized that auscultation was seldom employed during physical examinations, in part because it was considered "as uncomfortable for the doctor as it was for the patient" (1).

Laennec's breakthrough came in the course of caring for a plump young woman. Recognizing that he could not place his ear on her chest and recalling "the augmented impression of sound when conveyed through certain solid bodies," he rolled some sheets of paper into a cylinder, then placed one end over the patient's chest and the other at his ear. He found that he could hear the heart sounds more clearly than by direct auscultation (1).

Laennec then embarked on a series of experiments, testing different materials such as wood, cane, and paper, to see which would perform best. He settled on a foot-long hollow pipe of wood, which he first called, "the cylinder." Later, he named it the "stethoscope," from the Greek roots for "chest" and "inspect" $(1,4,6)$.

Three years after his innovation, in 1819, Laennec published "On Mediate Auscultation of the Lungs and Heart." In two volumes, its 3500 copies sold briskly, aided in part by the fact that early volumes were packaged with a wooden stethoscope. In the text he described normal breath sounds and a variety of "rhonchi," including terms such as egophony and rales, which are still widely used today. Later he introduced the term crackles.

Laennec also correlated these auscultatory signs with pathologic findings $(1,6)$. For example, he showed that the bleating sound of egophony is heard just above a pleural effusion, and that 
pectoriloquy indicates the presence of cavities in the lungs $(1,7)$. He also described the first and second heart sounds, though he was primarily interested in the lungs (4).

Many notable contributions followed. For example, Laennec established that the tubercle is the basic lesion in what was known in his day as phthisis, but later as tuberculosis $(1,4)$. He described and introduced the term "cirrhosis," from the Greek for "tawny," for the disordered hepatic fibrosis and regenerative nodules we now associate with this condition (4).

Laennec helped to set new standards for the depth and breadth of clinical observation and its correlation with postmortem findings. Working 75 years before the discovery of the $\mathrm{x}$-ray, Laennec could not observe pathologic changes in vivo, but he gleaned a remarkable amount of information from the autopsies he performed on his own patients $(4,8)$.

When Laennec finally received a faculty appointment at the College of France in 1822, followed by election to the French Academy of Medicine the following year, he did not have long to live $(1,8)$. He had suffered for at least 20 years from pulmonary tuberculosis, with symptoms including chronic productive cough. His short stature (5 feet, 2 inches) and general frailty suggest that he may have been suffering from the disease since childhood.

As Laennec's health began to decline, he left Paris and asked his nephew to auscultate his lungs using the stethoscope. Based on the young man's report, he concluded that he was suffering from tuberculosis. He died in August of 1826 of cavitary tuberculosis, leaving his papers and his most prized possession, his stethoscope, to his nephew (4).

\section{LEGACY}

Laennec could not have dreamt that sound waves in the form of ultrasound would one day make it possible to visualize the interior of the human body, but his unparalleled acoustic contributions 
to medicine stemmed from personal habits that remain as important as ever today. These habits can be cultivated by both educators and learners.

One such habit, which he shared with Auenbrugger, was a well-developed talent for music. Laennec was a gifted flautist, and some have speculated that his familiarity with the instrument may have planted the idea of a wooden cylinder. Even more importantly, Laennec's ear had been well developed by a lifelong passion for music, which enabled him to discern subtle differences in what he heard.

Laennec also cultivated a remarkable curiosity. He did not rest content with the content of medical lectures and textbooks of his day but instead sought to advance medical knowledge beyond the curriculum he had known as a student.

Laennec also developed his ability to form productive alliances with other eminent investigators. He realized that knowledge could best be advanced through collaboration, as reflected in his cofounding of the anatomical society, and he engaged in regular conversation and debate with his teachers and colleagues (3). He and the great physicians of his day not only learned from each other but also spurred one another on.

Laennec also cultivated his resilience. He knew loss as a child, encountered grave suffering as a teenager through his service as a military medic, and on graduation from medical school failed to receive an appointment to the medical faculty. But instead of giving up, he drew on such setbacks as learning opportunities, enhancing his own sense of determination to do good work and contribute to the lives of others.

Laennec also developed a disdain for political maneuvering. He threw himself into his work, which he allowed to speak for itself. And when honors came his way, he did not let them go to 
his head or rest on his laurels, but instead leveraged them into even greater scientific and medical contributions.

Finally, throughout his life, Laennec cultivated a deep moral and spiritual conviction. He devoted much of his clinical career to serving the poor. He was notoriously kind and enjoyed a reputation as an intensely religious person his whole life.

When it became clear that Laennec would die of the same disease that he had worked so hard to elucidate with his stethoscope through countless meticulous clinical and pathologic observations, he met his end with great courage and composure. He had seen his mother, his uncle, and several of his great teachers and colleagues die of tuberculosis, and he rejoiced in knowing that the years of his short life had redounded to the benefit of his fellow man. This is perhaps the best of all habits radiology's educators and learners could seek to cultivate. 


\section{References}

1. Sakula A. R T H Laennec $1781 \square 1826$ his life and work: a bicentenary appreciation. Thorax 1981; 36:81-90. doi:10.1136/thx.36.2.81.

2. Jay V. The legacy of Laennec. Arch Pathol Lab Med 2000; 124:1420-1421. 10.1043/0003-9985(2000)124<1420:TLOLN>2.0.CO;2.

3. de Saint-Maur PP. The birth of the clinicopathological method in France: the rise of morbid anatomy in France during the first half of the nineteenth century. Virchows Arch 2012; 460:109-117. doi:10.1007/s00428-011-1162-2.

4. Roguin A. Rene Theophile Hyacinthe Laennec (1781-1826): the man behind the stethoscope. Clin Med Res 2006; 4:230-235.

5. Atalic B. 200th anniversary of the beginning of clinical application of the Laennec's stethoscope in 1819. Acta Med Hist Adriat 2019; 17:9-18.

6. Yaqub F. Rene Theophile Hyacinthe Laennec. Lancet Respir Med 2015; 3:755-756. doi:10.1016/S2213-2600(15)00374-4.

7. Tomos I, Anna Karakatsani, Effrosyni D Manali, et al. Celebrating two cen-turies since the invention of the stethoscope. rene theophile hyacinthe Laennec (1781 $\square$ 1826). Ann Am Thorac Soc 2016; 13:1667-1670. doi:10.1513/AnnalsATS.201605-411PS.

8. Kligfield P. Laennec and the discovery of mediate auscultation. Am J Med 1981; 70:275278. doi:10.1016/0002-9343(81)90762-2. 